J. Bangladesh Acad. Sci., Vol. 42, No. 2, 129-136, 2018

DOI: https://doi.org/10.3329/jbas.v42i2.40040

\title{
PHENOLIC CONTENT ANALYSIS AND EVALUATION OF ANTINOCICEPTIVE, ANTIOXIDANT, ANTI-INFLAMMATORY POTENTIAL OF ALTERNANTHERA PUNGENS KUNTH
}

\author{
MD. SELIM HOSSAIN", MD. SOHEL RANA ${ }^{2}$, RAJIBUL ISLAM ${ }^{1}$, A. F. M MAHMUDUL ISLAM ${ }^{1}$ \\ Department of Pharmacy, Gono Bishwabidyalay, Mirzanagar, Savar, Dhaka-1344, Bangladesh
}

\begin{abstract}
The present study evaluated the analgesic, anti-inflammatory and antioxidant activities of Alternanthera pungens kunth.The ethanolic extract of Alternanthera pungens (EAP) showed analgesic effects by exerting ameliorated reaction time $40.79 \%$ and $44.74 \%$ at a dose of 250 and $500 \mathrm{mg} / \mathrm{kg}$,respectively, whereas standard was $41.78 \%$ by the hot plate test. Results of writhing inhibition were statistically significant $(\mathrm{p}<0.05)$ when compared to control. In addition to that, anti-inflammatory effects were also evaluated against denaturation of protein and the result was significant. Scavenging activity of EAP was $80.95 \%$ at the concentration of $800 \mu \mathrm{g} / \mathrm{mL}$. Moreover, HPLC-DAD analysis of EAP was also carried out to determine the presence of phenolic constituents \& noted the presence of epicatechin,vanillin, $p$-coumaric acid etc. These studies inferred that EAP possesses analgesic, antiinflammatory and antioxidant potential which might be due to presence of phytochemicals like flavonoids, tannins and phenolic compounds.
\end{abstract}

Keywords: EAP, analgesic, anti-inflammatory, antioxidant, phenolic compounds.

\section{INTRODUCTION}

Medicinal plants play an appealing role in alleviation of several human ailments. Many civilizations and cultures have a confirmed credence on these cures to treat their health related issues. Plants are the rich genesis of the active chemical ingredients such as polyphenols and flavonoids, glycosides, alkaloids, and tannins (Škrovánková et al. 2012). Traditional medical practitioners use a wide range of medicinal plants for treatment of various ailments in Bangladesh. Bangladesh is rich in flora and fauna; more than five hundreds potential medicinal plants are present here, having traditional uses (Ghani, 2002). Most often, a desired biological response is not due to the presence of one component, but the presence of a medley of bioactive plant components. Medicinal plants are a rich source of antioxidants, which has the ability to ameliorate oxidative damage in tissues and prevents degenerative diseases such as cardiovascular diseases, cancer, diabetes and aging (Gutteridge and Halliwell, 2010; Ndhlala et al. 2010). Despite the progress that has occurred recently in the development of pain therapy, there is still need for effective and potent anodyne, especially for the treatment of chronic pain (Calixto et al. 2000). The existing synthetic therapeutic agents are also costly and not easily available to the rural people of the developing country. On the other hand, plant derived preparations are achieving much importance in therapeutic applications owing to cheap in price, easily available and have modicum side effects. In this manner, the use of traditional medicine and medicinal plants in most developing countries is widely observed in the treatment of various diseases, including prevention and management

\footnotetext{
* Corresponding author: < selimmd36@ gmail.com >.

${ }^{1}$ Department of Pharmacy, Gono Bishwabidyalay, Mirzanagar, Savar, Dhaka-1344, Bangladesh.

${ }^{2}$ Department of Pharmacy, University of Asia Pacific, Dhaka-1215, Bangladesh.
} 
of pain, inflammation and other oxidative stress associated diseases such as cancer, atherosclerosis, aging and neurodegenerative ailments (Beg et al. 2011; Jain et al. 2014). The genus Alternanthera, under the family of Amaranthaceae is a medicinally important plant which contains volatile constituents, essential amino acids, flavonoids, glycosides and steroids (Khatun et al. 2012). The common name of Alternanthera pungens Kunth is khaki weed which is distributed in Central and South America, some tropical countries including Bangladesh (Wild, 1995). It is a perennial herb and its stem is hairy, $10-50 \mathrm{~cm}$ long, prostrate and occasionally develop roots from the nodes. Leaves are green and are generally 0.5 to $4.5 \mathrm{~cm}$ long and 0.3 to $2 \mathrm{~cm}$ wide (Naidu, 2012). Traditionally, this plant is used as painkiller, for stomachache, swelling and nasopharyngeal infections and also reported for lactation stimulus in veterinary (Burkill, 1985).

However, the scientific validation of EAP for the use in inflammation and pain related disorders have not been reported earlier. The present paper deals with rudimentary phytochemical composition, antioxidant and anti-inflammatory activities of EAP.The EAP was also subjected to HPLC-DAD analysis for determining the presence of phenolic constituents.

\section{MATERIALS AND METHODS}

\section{Preparation of extracts}

The plant was recognized by its local appellation and garnered from Sitakunda, Chittagong, Bangladesh. The plant sample after authentication was deposited (Accession No. DACB 40178) at the Bangladesh National Herbarium, Mirpur, Dhaka. Whole plants of A.P were first powdered, then extracted $(72 \mathrm{~h})$ with ethanol in a ratio of 1:6. The filtered extract was subjected to evaporation on rotary evaporator
(Bibby RE-200, Sterilin Ltd., UK). The crude extracts were collected and preserved at $+4^{0} \mathrm{C}$ for in vitro and in vivo experiments.

\section{Phytochemical Analysis}

Qualitative: The freshly prepared crude extract was qualitatively analyzed for the identification of chemical constituents. The tests were performed by the method described by Harborne and Sazada et al. and in each test 10\% (w/v) solution of the extract was taken, unless otherwise mentioned in individual test (Evans, 1989). Different tests, including alkaloids by Dragrendroff's reagent, flavonoids by $\mathrm{HCl}$, carbohydrates by Molisch's reagent, terpenoids by Salkowski method and reducing sugar by Fehling's solution were carried out.

Quantitative assay: Total phenolic as well as flavonoid contents were quantified by the standared procedures.

\section{Total Phenolic contents (TPC)}

The total phenolic content of of EAP was determined using Folin-ciocalteu reagent with minor modifications ( $\mathrm{Yu}$ et al. 2002). Estimation of TPC was carried out as mg of gallic acid equivalents (GAE) per gram of dry extract/fraction by using gallic acid standard curve, $y=0.003 x+0.204 ; R^{2}=0.956$.

\section{Total Flavonoid content (TFC)}

Total flavonoid was determined using the aluminum chloride calorimetric method described by Wang and Jiao (Wang and Jiao, 2000). The Total content of flavonoid compounds in EAP was determined in quercetin equivalents using the quercetin standard curve, $y=0.003 x+0.109 ; \mathrm{R}^{2}=$ 0.915 .

\section{In vitro Antioxidant assay}

\section{DPPH Free Radical Scavenging Assay:}

1,1-diphenyl-2-picrylhydrazyl (DPPH) is a reactive free radical and acts as oxidizing agent. 
The scavenging of DPPH free radical is indicated as deep violet color being turned into pale yellow or colorless (Braca et al. 2001). Radical Scavenging activity was calculated using the following equation :

$$
\% \text { Inhibition }=\left(1-\frac{\text { Absorbance of Sample }}{\text { Absorbance of Control }}\right) \times 100
$$

High Performance Liquid Chromatography (HPLC) DAD analysis

Detection and quantification of selected phenolic compounds in EAP were determined by HPLCDAD analysis as described by Jahan et al. (2014) with some modifications. It was carried out on a Dionex UltiMate 3000 system equipped with a quaternary rapid separation pump (LPG3400RS) and photodiode array detector (DAD3000RS).

\section{Evaluation of Analgesic Activity:}

Young Swiss-albino mice aged 4-5 weeks, mean weight 25-30 gm was used for the experiment. Experiments in which animal involved were conducted according to the UK Home Office Regulations (UK Animals Scientific Procedures Act 1986) and the 'Principles of Laboratory Animal Care' (National Institutes of Health publication no. 86-23, revised 1985).

\section{Hot plate test method}

The hot plate test method was performed to evaluate the analgesic activity in accordance with the method explicated previously with exiguous modification (Mahomed and Ojewole, 2004). The animals were placed on Eddy's hot plate at a temperature of $55 \pm 1^{\circ} \mathrm{C}$. After oral administration of the samples, the reaction time was recorded when animals licked their fore or hind paws, or jumped prior to and 0, 30, 60,
120,180 and $240 \mathrm{~min}$. The antinociceptive response latency was recorded.

\section{Acetic acid induced writhing method}

The analgesic activity of the EAP was also evaluated using acetic acid induced writhing method in mice (Ahmed et al. 2004). After intraperitoneal administration of acetic acid solution, number of writhing they made were viewed.

In vitro anti-inflammatory activity test against denaturation of protein

The anti-inflammatory activity of EAP was studied by using inhibition of albumin denaturation technique which was studied according to Mizushima et al. followed with minor modifications (Mizushima and Kob, 1968). Percentage inhibition of protein denaturation was calculated from the control applying the following equation:

\%inhibition $=[\{$ Abs of control $-\mathrm{Abs}$ of test $/ \mathrm{Abs}$ of control\} X 100

\section{Statistical analysis}

The analgesic data are expressed as the mean \pm SEM analyzed by one-way analysis of variance (ANOVA) and Dunnett's $t$-test was used as the test of significance. $\mathrm{P}$ value $<0.05$ was considered as the minimum level of significance.

\section{RESULTS}

Phytochemical analysis

Phytochemical screening tests ascertained the presence of various bioactive compounds. Most eminent of them are tannins, alkaloid, flavonoids, saponins, gums, terpenoids, phenols and resins. It is shown in Table 1. Total phenolic as well as flavonoid contents were $12.81 \pm 0.15$

Table 1. Bioactive compments of EAP evaluated by phytochemical screening

\begin{tabular}{cccccccccc}
\hline Entityin EAP & Tannins & Flavonoids & Saponins & Gum & Steroids & Alkaloids & Terpenoids & Phenol & Resin \\
\hline Results & + & + & + & + & - & + & & + & + \\
\hline
\end{tabular}

$(+)$ indicates presence and $(-)$ indicates the absence of the respective phytochemical. 
mg GAE/g extracts and $17.18 \pm 0.25 \mathrm{mg}$ QE/g Analgesic activity

extracts respectively.

HPLC-DAD analysis for determination of phenolic compounds

Chromatography segregated phenolic

Hot plate test

compounds of EAP as shown in Table $2 . \quad 3^{\text {rd }} \mathrm{hr}$ of study, EAP has enhanced the reaction

Table 2. Contents of polyphenolic compounds in the ethanol extract of Alternanthera pungens $(\mathbf{n}=5)$

\begin{tabular}{lcc}
\hline Polyphenolic & \multicolumn{2}{c}{ Ethanol extract of $\boldsymbol{A} . \boldsymbol{P}}$. \\
\cline { 2 - 3 } Compounds & Content (mg/100 g of dry extract) & $\%$ RSD \\
\hline Epicatechin (ECA) & 83.55 & 1.88 \\
vanillin (VL) & 4.14 & 0.06 \\
p-coumaric acid (PCA) & 5.55 & 0.09 \\
Trans-ferulic acid (FA) & 17.36 & 0.54 \\
ellagic acid (EA) & 11.49 & 0.18 \\
myrecctin (MC) & 8.32 & 0.11
\end{tabular}

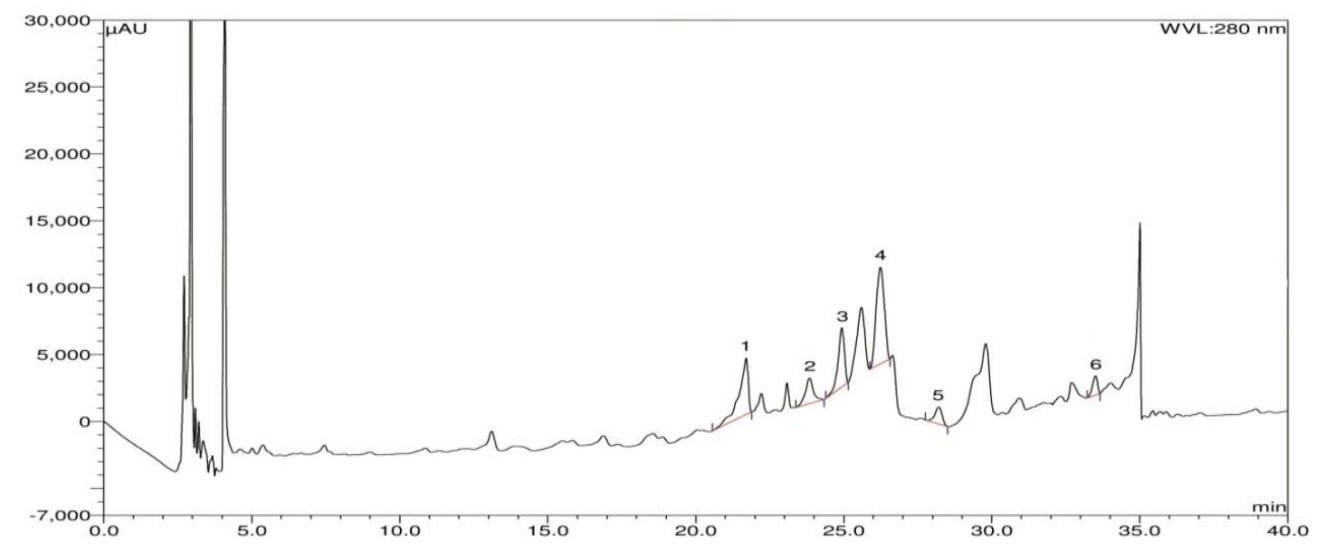

Fig 1. HPLC chromatogram of ethanol extract of Alternanthera pungens.Peaks: 1, (-)-epicatechin; 2, vanillin; 3, p-coumaric acid; 4, trans-ferulic acid; 5, ellagic acid; 6, myricetin.

Experimental compounds in EAP resulted in time 40.79 and $44.74 \%$ at a dose of 250 and 500 identifying, including (-) -epicatechin (ECA), $\mathrm{mg} / \mathrm{kg}$ respectively whereas standard was vanillin (VL), p-coumaric acid (PCA), trans- $41.78 \%$ that is nearest to EAP. The results were ferulic acid (FA), ellagic acid (EA) and found to be statistically significant $(\mathrm{p}<0.01)$. myricetin (MC) and copious amount of (-)epicatechin (ECA) and trans-ferulic acid (FA) (Fig1). 
Table 3. Analgesic activity of the ethanol extract of Alternanthera pungens (hot plate method)

\begin{tabular}{lccccc}
\hline Treatment & \multicolumn{5}{c}{ Drug reaction time } \\
\cline { 2 - 6 } Group & $\mathbf{0}$ hour & $\mathbf{1}$ hour & $\mathbf{2}$ hours & $\mathbf{3}$ hours & $\mathbf{4}$ hours \\
Control & $8.04 \pm 1.21$ & $11.06 \pm 1.83$ & $10.22 \pm 1.054$ & $10.86 \pm 1.41$ & $9.7 \pm 1.35$ \\
\hline Standard & $12.76 \pm 0.8$ & $18.16 \pm 0.73$ & $20.96 \pm 1.44 * * *$ & $21.92 \pm 1.53^{* * *}$ & $16.06 \pm 1.402$ \\
& & $(29.74)$ & $(39.2)$ & $(41.78)$ & $(20 . .54)$ \\
\hline $\begin{array}{c}\boldsymbol{E A P} \mathbf{2 5 0} \\
\mathbf{~ m g / k g}\end{array}$ & $7.91 \pm 0.67$ & $10.28 \pm .356$ & $12.26 .48 \pm 1.1 * *$ & $13.36 \pm 1.399 * * *$ & $9.78 \pm 0.769 * *$ \\
& & 23 & 35.23 & 40.79 & 19.12 \\
\hline $\begin{array}{c}\boldsymbol{E A P} \mathbf{5 0 0} \\
\mathbf{~ m g / k g}\end{array}$ & $8.46 \pm 1.46$ & $12.02 \pm 1.084$ & $14.20 \pm 0.480^{* * *}$ & $15.31 \pm 0.237 * * *$ & $11.4 \pm 1.37$ \\
& & 29.62 & 40.42 & 44.74 & 25.79 \\
\hline
\end{tabular}

SEM $=$ Standard error of Mean, $n=$ number of mice. All values are mean \pm SEM, $\mathrm{n}=5$. The minimum value of $\mathrm{p}<0.05$ was considered significant. ${ }^{*} \mathrm{p}<0.05$, ** $\mathrm{p}<0.01, * * * \mathrm{p}<0.001$ as compared with control group.

Acetic acid induced writhing method

The prohibition of licking response in mice shown in Fig. 2. The oral administration of both doses of EAP had momentous $(\mathrm{p}<0.001)$ attenuation on acetic acid-induced abdominal writhes in mice. The percent prohibition of
In vitro antioxidant assay

DPPH contains an odd number of electrons, responsible for the absorbance at $517 \mathrm{~nm}$. The DPPH radical scavenging activity of EAP and ascorbic acid (standard) are represented in Fig 3.
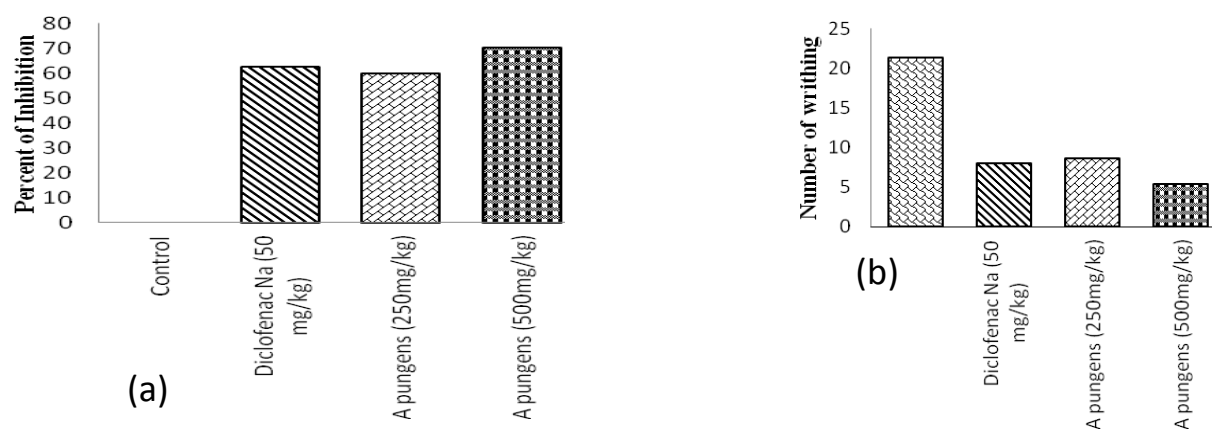

Fig 2. Effect of EAP of acetic acid-induced writhing in mice. (a) Percent inhibition of pain, (b) Number of writhing. Data are represented as the mean \pm SEM, $(n=5) ; * *<<0.001$ considered statistically significant as compared to control.

writhing response showed by the extract was 59.81 and 70.1 at 250 and $500 \mathrm{mg} / \mathrm{kg}$ doses, respectively.
The scavenging activity of EAP $(80.95 \%)$ was analogous to that of standard ascorbic acid $(92.02 \%)$ at the concentration of $800 \mu \mathrm{g} / \mathrm{mL}$. 


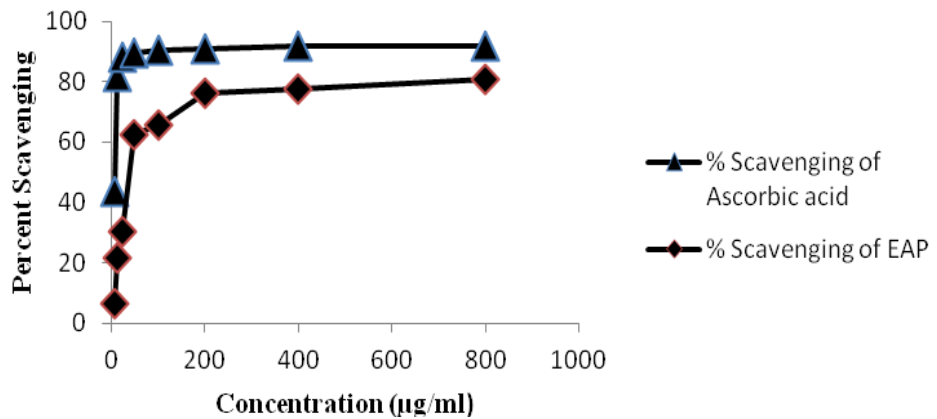

Fig 3. DPPH scavenging activity of EAP and ascorbic acid (standard)

\section{Anti-inflammatory assay}

EAP $\quad(100-500 \mu \mathrm{g} / \mathrm{mL})$ showed significant inhibition of denaturation of egg albumin in a concentration dependent manner (Fig 4).

The most prominent inhibition of $63.14 \%$ at 500 $\mu \mathrm{g} / \mathrm{mL}$ concentration of EAP was observed by HPLC-DAD analysis. Earlier investigations suggested that the use of acetic acid induced writhing and hot plate tests for the evaluation of peripheral and centrally acting analgesic drugs respectively (Koster et al. 1959).

The anodyne activity was evaluated by writhing

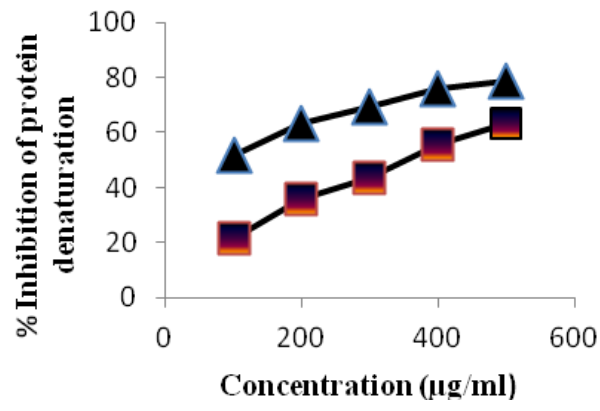

- $\mathbf{-}$ \% Inhibition of protein denaturation by Diclofenac $\mathrm{Na}$

- $-\%$ Inhibition of protein denaturation by EAP

Fig 4. Percent inhibition of protein denaturation by diclofenac sodium and EAP

while standard diclofenac sodium showed inhibition of $78.69 \%$ at the same concentration.

\section{DISCUSSION}

The study reports the activity of EAP on a discrete experimental animal model of ache and inflammation. Antioxidant properties of EAP were also estimated with the help of DPPH method. EAP inhibited the nociception produced by hot plate and writhing induced by acetic acid with greater momentous. It ascertained the presence of anti-inflammatory phenolic compounds (e.g. epicatechin) in EAP test which has been reported to be useful for investigation of peripheral antinociceptive activity and carried out as a chemical pain model (Abdollahi et al. 2003; Golshani et al. 2004). The hot plate test was performed as a thermal pain model which is widely known as useful for study of the central mechanism of analgesic activity. Diclofenac sodium increased the pain threshold with greater moments throughout the observation period of 1-3h. The EAP showed a dose dependent, significant antinociceptive activity in both animal models of pain. Acetic acid believed to increase the $\mathrm{PGE}_{2}$ and $\mathrm{PGF}_{2 \alpha}$ in 
peritoneal fluid (Krasteva et al. 2008). However, in two models of evaluation, the EAP showed analogous results with diclofenac sodium. Therefore, the analgesic activity shown in two models of pain indicated centrally and peripherally mediated antinociceptive properties of EAP.

In the current study, the protein denaturation bioassay was chosen for in vitro assessment of the anti-inflammatory property of EAP. Denaturation of the tissue proteins is one of the well-documented reason of inflammation and arthritic disorders. Production of auto-antigens in certain arthritic diseases may be due to denaturation of proteins in vivo (Opie, 1962; Umapathy et al. 2010). It is already proved that conventional NSAID's like Diclofenac sodium not only acts by the inhibition of endogenous prostaglandin production by blocking the COX enzyme but also by prevention of denaturation of proteins. Hence, using agents that can impede protein denaturation would be worthwhile for anti-inflammatory drug development. In vitro anti-inflammatory effect of EAP was estimated against denaturation of egg albumin. The results are summarized in Fig 4. The present findings exhibited a concentration-dependent inhibition of protein (albumin) denaturation by EAP as well as diclofenac sodium at the same concentration range of $100-500 \mu / \mathrm{mL}$. So, it can be inferred that EAP has potential antiinflammatory effects as compared with standard (diclofenac sodium). So, the secondary metabolites like phenolic compounds and tannins, which were found in initial phytochemical screening might be responsible for this activity.

The EAP exhibited significant antioxidant activity. The results suggest that EAP might serve as a potent therapeutic agent for scavenging of free radicals and the maintenance of pathological conditions caused by oxidative stress. The observed antioxidant effect of the plant extract could be assigned to the presence of polyphenolic compounds. The results are in line with the previous studies which indicated the free radical scavenging activity of plant extracts correlated with the phenolic content (Omoruyi et al. 2012; Jain et al. 2014).

\section{CONCLUSION}

In conclusion, EAP displayed analgesic, antiinflammatory and antioxidant activity and supported the traditional use of this plant in pain relief. Further study is needed to identify the active compounds present in this extract and to elucidate the mechanisms involved in its analgesic properties.

\section{REFERENCES}

Abdollahi M, Karimpour H, Monsef-Esfehani HR. 2003. Antinociceptive effects of Teucrium polium $\mathrm{L}$ total extract and essential oil in mouse writhing test. Pharmacol Res. 48: 31-35.

Ahmed OH, Husni MHA, Anuar AR, Hanafi MM, Angela EDS.2004. A modified way of producing humic acid from composted pineapple leaves. J Sustain Agr. 25: 129-139.

Beg, S, Swain S, Hasan H, Barkat MA and Hussain MS. 2011. Systematic review of herbals as potential anti-inflammatory agents: Recent advances, current clinical status and future perspectives. Pharmacogn Rev. 5: 120-137.

Braca A, Tommasi ND, Bari LD, Pizza C, Politi M, Morelli I. 2001. Antioxidant principles from Bauhinia terapotensis. J. Nat. Prod. 64: 892-895.

Burkill. 1985. The useful plants of west tropical Africa. Royal Botanic Gardens, Kew, UK. vol. 3.

Calixto JB, Beirith A, Ferreira J, Santos ARS, Filho VC, Yunes RA. 2000. Naturally occurring antinociceptive substances from Plants. Phytoher Res. 14: 401-418. 
Evans WC. 1989. Trease and Evan's Textbook of Pharmacognosy, $13^{\text {th }}$ Ed, Cambridge University Press, London, 546.

Ghani A. 2002. Medicinal plants of Bangladesh with chemical constituents and uses. $2^{\text {nd }} E d$. Dhaka: Asiatic Society of Bangladesh.

Golshani S, Karamkhani F, Monsef-Esfehani HR, Abdollahi M. 2004. Antinociceptive effects of the essential oil of Dracocephalum kotschyi in the mouse writhing test. J. PharmPharm Sci. 7: 76-79.

Gutteridge JM, Halliwell B. 2010. Antioxidants: Molecules, medicines, and myths. Biochem. Biophys Res Commun. 4: 561-4.

Jahan IA, Akbar PN, Khan N, Khan TA, Rahman MM, Hira A, Hossain. 2014. Comparative Study of anti-nociceptive activity and phenolic content of the ethanol extracts of Piper nigrum and Piper longum fruits. Int J. Pharm Sci Rev Res. 1: 47-52.

Jain P, Hossain KR, Mishu TR and Reza HM. 2014. Antioxidant and antibacterial activities of Spondiaspinnata Kurz. leaves. European J. Med. Plants. 4: 183-195.

Khatun F, Zaman F, Mosaiab T, Mostafa F, Zaman M, Rehana F, Nasrin D, Jamal F, Nahar N, Rahmatullah M. 2012. Evaluation of antinociceptive and antihyperglycemic activities in methanol extracts of whole plants of Alternanthera philoxeroides (Mart.) Griseb. (Amaranthaceae) in mice. Pak. J. Pharm. Sci. 25: 583-587.

Koster R, Anderson M, Debeer EJ. 1959. Acetic acid for analgesic screening. Federation Proceedings. 18: 412-418.

Krasteva I, Momekov G, Zdraveva P, Konstantinov S, Nikolov S. 2008. Antiproliferative effects of a flavonoid and saponins from Astragalus hamosus against human tumor cell lines. Pharmacog Mag. 4: 269.

Mahomed IM, Ojewole JAO. 2004. Analgesic, anti-inflammatory and Anti-diabetic properties of Harpagophytum procumbens DC (Pedaliaceae) secondary root aqueous extract. Phytother Res. 12: 982-989.
Mizushima Y, Kobayashi M.1968. Interaction ofanti-inflammatory drugs with serum proteins, especially with some biologically active proteins. J. Pharm. Pharmacol. 20: $169-173$

Naidu, V. S. G. R. 2012. Hand Book on Weed Identification. Directorate of Weed Science Research, Jabalpur, India.

Ndhlala AR, Moyo M, Van Staden J. 2010. Natural antioxidants: fascinating or mythical biomolecules? Molecules. 10: 6905-30.

Omoruyi BE, Bradley G, Afolayan AJ. 2012. Antioxidant and phytochemical properties of Carpobrotus edulis (L.) bolus leaf used for the management of common infections in HIV/AIDS patients in Eastern Cape Province. BMC Complent Altern Med. 12: 215.

Opie EL.1962. On the relation of necrosis and inflammation to denaturation of proteins. J. Exp. Med. 115: 597-608.

Škrovánková S, Mišurcová L, Machů L. 2012.Antioxidant activity and protecting health effects of common medicinal plants. Adv Food Nutr Res. 67: 75-139.

Umapathy E, Ndebia EJ, Meeme A, Adam B, Menziwa P, Nkeh-Chungag BN. 2010. An experimental evaluation of Albuca setosa aqueous extract on membrane stabilization, protein denaturation and white blood cell migration during acute inflammation. J. Med. Plants Res. 4: 789-95.

Wang SY, Jiao H. 2000. Scavenging capacity of berry crops on superoxide radicals, hydrogen peroxide, hydroxyl radicals, and singlet oxygen. J. Agric. Food Chem. 48: 5677-5684.

Wild, H., 1995. Common Rhodesians weeds. Salisbury: Government Printer.

Yu L, Haley S, Perret J, Harris M, Wilson J, Qian M. 2002. Free radical scavenging properties of wheat extracts. J. Agric. Food Chem. 50: 1619-1624.

(Received revised manuscript on 13 August 2018) 